\title{
Recent Insights into the Management of Pleural Infection
}

\section{Maged Hassan (1D) \\ Shefaly Patel ${ }^{2}$ \\ Ahmed S Sadaka' \\ Eihab O Bedawi ${ }^{2}$ \\ John P Corcoran ${ }^{3}$ \\ José M Porcel (1D ${ }^{4}$}

'Chest Diseases Department, Alexandria University Faculty of Medicine, Alexandria, Egypt; ${ }^{2}$ Oxford Centre for Respiratory Medicine, Oxford University Hospitals, Oxford, UK; ${ }^{3}$ Department of Respiratory Medicine, University Hospitals Plymouth NHS Trust,

Plymouth, UK; ${ }^{4}$ Department of Internal Medicine, Arnau de Vilanova University Hospital, Lleida, Spain
Correspondence: Maged Hassan

Chest Diseases Department, Alexandria

University Faculty of Medicine,

Alexandria, Egypt

$\mathrm{Tel}+203591-8662$

Email magedhmf@gmail.com

\begin{abstract}
Pleural infection in adults has considerable morbidity and continues to be a lifethreatening condition. The term "pleural infection" encompasses complicated parapneumonic effusions and primary pleural infections, and includes but is not limited to empyema, which refers to collection of pus in the pleural cavity. The incidence of pleural infection in adults has been continuously increasing over the past two decades, particularly in older adults, and most of such patients have comorbidities. Management of pleural infection requires prolonged duration of hospitalization (average 14 days). There are recognized differences in microbial etiology of pleural infection depending on whether the infection was acquired in the community or in a health-care setting. Anaerobic bacteria are acknowledged as a major cause of pleural infection, and thus anaerobic coverage in antibiotic regimens for pleural infection is mandatory. The key components of managing pleural infection are appropriate antimicrobial therapy and chest-tube drainage. In patients who fail medical therapy by manifesting persistent sepsis despite standard measures, surgical intervention to clear the infected space or intrapleural fibrinolytic therapy (in poor surgical candidates) are recommended. Recent studies have explored the role of early intrapleural fibrinolytics or first-line surgery, but due to considerable costs of such interventions and the lack of convincing evidence of improved outcomes with early use, early intervention cannot be recommended, and further evidence is awaited from ongoing studies. Other areas of research include the role of routine molecular testing of infected pleural fluid in improving the rate of identification of causative organisms. Other research topics include the benefit of such interventions as medical thoracoscopy, high-volume pleural irrigation with saline/antiseptic solution, and repeated thoracentesis (as opposed to chest-tube drainage) in reducing morbidity and improving outcomes of pleural infection. This review summarizes current knowledge and practice in managing pleural infection and future research directions.
\end{abstract}

Keywords: pleural infection, empyema, respiratory infections, pneumonia

\section{Background}

Pleural space infection is a serious medical condition that was first described by physicians in ancient Egypt more than 4,000 years ago. ${ }^{1,2}$ Pleural infection was a fatal disease up until the introduction of closed-tube drainage for treatment of empyema in the late 19th century, which resulted in a substantial reduction in mortality. ${ }^{3}$ Another leap in managing pleural infection was the discovery of antibiotics in the first half of the 20th century, which saw a steady decline in fatalities from the condition. ${ }^{4}$ However, pleural infection continues to cause considerable morbidity and remains a life-threatening disease, with up to $15 \%$ of such patients presenting to medical care in a critical state requiring organ support. ${ }^{5,6}$ 
The terminology to describe pleural infection has varied over time, with terms describing the presumed underlying etiology or physical appearance of infected fluid. The disease is termed "complicated parapneumonic effusion" to separate it from simple (uninfected) parapneumonic effusions that accompany up to half the cases of pneumonia. $^{7}$ These terms do not cover primary pleural infections occurring without contiguous lung infection, which make up almost two-thirds of the disease burden. ${ }^{8}$ "Empyema thoracis" is a term used to describe accumulation of pus in the pleural space, but it is recognized now that infected fluid can appear serous or turbid, with diagnosis confirmed on biochemical and/or microbiological tests. It has even been found that nonpurulent infections herald worse prognosis. ${ }^{9,10}$ Therefore, "pleural infection" is an all-encompassing term that is preferred in current literature.

This review aims to provide an overview of different aspects of the etiology and management of adult pleural infection, providing an update on diagnosis and treatment and highlighting knowledge gaps and future research directions. We do not cover pleural infection due to tuberculosis.

\section{Epidemiology}

Epidemiological studies from North America, ${ }^{11,12}$ Western Europe, ${ }^{13,14}$ and East Asia ${ }^{15}$ have shown that incidence of pleural infection in the second decade of the 21 st century is 6.7-9.9 cases per 100,000 population. The incidence of pleural infection nearly doubled from the first to the second decade of the 21 st century. ${ }^{11,12,14}$

In Europe, the US, Canada, and Australia, 5,6,8,13,14,16 the average age of patients diagnosed with pleural infection is 58-63 years. However, a recent systematic review pointed out a discrepancy in the age bracket of adult patients with pleural infection between high-income and low(er)-income countries, where patients in the latter group tended to be 15 years younger on average. ${ }^{17}$ The same systematic review found high prevalence of comorbidity in patients with pleural infection (median prevalence $72 \%$ ), with no difference in prevalence between patients from high-income and lower-income countries.

Treating pleural infection requires long hospital admission, averaging 14-17 days., ${ }^{5,6,11,14,18}$ Together with the high comorbidity burden, the increasing use of expensive medications, and increasing rates of referral to surgery ${ }^{15}$ translate into high health-care costs of managing pleural infection. ${ }^{6,15}$ Despite this increasing economic burden, the last decade has seen the rate of fatal pleural infection double, ${ }^{12}$ with a similar rise in 30-day mortality rates. ${ }^{14}$

\section{Pathophysiology}

It is estimated that $20 \%-50 \%$ of patients with communityacquired pneumonia (CAP) have evidence of parapneumonic effusion. However, only a small proportion of patients with CAP develop true pleural infection. ${ }^{19}$ Factors predictive of this complication are not entirely understood. The currently reported incidence is skewed toward older agegroups, which tend to be correlated with more multimorbidity and immunosuppressed states. ${ }^{14,20,21}$ The latter could also be a factor associated with the relatively high mortality reported in adult disease, which contrasts with the incidence and mortality profile of pleural infection in children. $^{22}$

In one study, pneumonia severity was not shown to predict evolution of pleural infection, but CRP $>100 \mathrm{mg} / \mathrm{L}$, platelet count $>400,000 / \mu \mathrm{L}$, serum albumin $<3 \mathrm{~g} / \mathrm{dL}$, serum sodium $<130 \mathrm{mmol} / \mathrm{L}$, and substance abuse (intravenous drugs/alcohol) were predictive. ${ }^{23}$ Other predisposing factors include diabetes, severe liver disease, renal dysfunction, and immunodeficiency. Smokers have been found to have a relatively higher incidence of parapneumonic effusion, and tobacco smoking is more prevalent among those who suffer from pleural infection. ${ }^{14,24}$ However, evidence of a direct relation between pleural infection and smoking is lacking. ${ }^{24}$

\section{Pathogenesis}

The normal pleural space accommodates $0.26 \mathrm{~mL} / \mathrm{kg}$ of pleural fluid, which is kept in balance through a process of parietal pleura formation and resorption. ${ }^{25}$ Pleural effusion results when this fine balance governed by Starling's forces is disturbed. Pleural infection is associated with increased permeability in the mesothelial layer and invasion of bacteria into the sterile pleural space, leading to collection of an exudative effusion beyond the drainage capacity of the parietal pleura. The lack of radiological evidence of pneumonia in $56 \%$ and $73 \%$ of communityacquired (CA) and hospital-acquired (HA) pleural infections, respectively, together with the different microbial profiles infecting the pleural space prove a likely role for hematogenous spread in pleural infections. ${ }^{8}$ Other routes of entry into the pleural space include rupture of a subpleural focus of infection or transdiaphragmatic spread of abdominal infection. 
Pleural infection evolution passes through stages that tend to be temporally variable among different patients, but are classically composed of three phases. ${ }^{7}$ The initial exudative phase is the result of proinflammatory mediators, such as TNF $\alpha$, IL6, and IL8.This is followed by a fibrinopurulent phase, which involves bacterial invasion of the pleural space. This results in an increase in plasminogen-activator inhibitors and $\mathrm{TNF} \alpha$, leading to fibrin deposition with loculation and formation of septations. The walled-off bacteria and associated phagocytic activity of neutrophils cause an increase in lactate dehydrogenase (LDH), lactic acid production, and consumption of pleural fluid glucose. These biochemical changes are a hallmark of infected pleural effusions. It has been suggested that the acidic medium of the pleural fluid, which is suboptimal for growth, might drive bacteria toward the surface of the pleural membranes. This was based on the finding that ultrasound-guided pleural biopsies increase the diagnostic microbiological yield over pleural fluid samples. ${ }^{26}$ The final stage is the organization stage, which is characterized by pleural thickening and formation of an inelastic visceral pleural peel, leading to lung entrapment. This follows fibroblasts proliferating from both pleural layers, a process thought to be associated with the release of TGF $\beta$ and PDGF. Owing to the deposition of a collagen-rich fibrin matrix in the pleural space, the use of fibrinolytic therapy at this stage is likely to be futile. Mitigating the release and effects of fibrogenic mediators is a potential target for future therapy. ${ }^{7}$

\section{Microbiology}

Understanding the microbiology of pleural infection is crucial for appropriate initial antibiotic choice. The positive yield from pleural fluid culture is on average $56 \%$, and thus in a proportion of cases the whole antibiotic course is empirical.

The commonest organisms causing CA pneumonia are Streptococcus pneumoniae and atypical bacteria (such as Mycoplasma and Legionella spp.), but the pattern is different in pleural infection. Studies applying molecular techniques to identify pathogens in infected pleural fluid samples were able to identify atypical bacteria in only 0 $0.5 \%$ of cases ${ }^{28,29}$ For this reason, pleural disease guidelines recommend against using macrolides in treating pleural infection. ${ }^{1}$ The probable explanation for the difference in microbiology between pleural infection and pneumonia is the hypoxic nature of the pleural space, which favors the growth of strictly and facultatively anaerobic bacteria more than other organisms. ${ }^{28,30}$

A recent systematic review on the microbiology of pleural infection in adults reported that Gram-positive cocci (namely Staphylococcus aureus, viridans-group streptococci (VGS), and S. pneumoniae, in descending order of frequency) were the commonest organisms implicated in causing pleural infection. ${ }^{27}$ They were followed by aerobic Gram-negative bacilli (chiefly Enterobacteriaceae and Pseudomonas spp.) and anaerobic bacteria. Grijalva et al reported that over the past two decades, the rates of adult pleural infection due to VGS and S. aureus have increased relative to other organisms. ${ }^{12}$ Alarmingly, the rate of occurrence of drug-resistant $S$. aureus pleural infection has increased by $25 \%$ in the last decade. ${ }^{27}$ The systematic review highlighted substantial variations in the rates of isolation of certain organisms in infection (whether CA or HA). The relative contribution of different microorganisms/groups is summarized in Table $1 .^{27}$

Variability by geography has also been highlighted by a systematic review stressing the importance of awareness of local/national patterns of microbiology and antibiotic resistance for appropriate antimicrobial prescribing. This variation is exemplified by the high incidence of pleural infections due to Klebsiella spp. in patients from East Asia. ${ }^{31-33}$ Patients residing in the subtropics have higher rates of infection by Gram-negative bacteria generally, ${ }^{27}$ and this has been hypothesized to be related to higher ambient temperature and humidity, similar to what has been reported with other infections. ${ }^{34}$ Interestingly, a retrospective study from the UK found that Gramnegative bacteria were more commonly isolated from infected pleural fluid in the summer months, suggesting a seasonal pattern of microbiology. ${ }^{35}$

The central contribution of microaerophilic bacteria (VGS) and anaerobic bacteria in pleural infection supports the role of certain risk factors in the causation of infection. Pleural infection is commonly seen in patients with poor dentition, a condition that allows flourishing of these bacteria in the oral cavity. Such microbes are then either aspirated, causing parapneumonic pleural infection, or reach the pleura via the bloodstream. ${ }^{36}$ These organisms commonly coinfect the pleural space together with other aerobic bacteria. Under optimum culture conditions, up to $61 \%$ of positive pleural fluid cultures yield mixed growth of anaerobic and/or aerobic bacteria. ${ }^{37}$ The curious exception are S. pneumoniae bacteria, which do not tend to coinfect the pleural space with other organisms. ${ }^{38}$ It is 
Table I Common micro-organisms implicated in communityacquired and hospital-acquired pleural infections

\begin{tabular}{|c|c|}
\hline $\begin{array}{l}\text { Community-acquired } \\
\text { infection }\end{array}$ & Hospital-acquired infection \\
\hline Gram-positive aerobes $65 \%$ & Gram-positive aerobes $51.5 \%$ \\
\hline $\begin{array}{l}\text { - Viridans group streptococci } \\
26.6 \% \\
\text { - Streptococcus pneumoniae } 18.2 \% \\
\text { - Staphylococcus aureus } 15.3 \% \\
\text { (67\% methicillin-sensitive) }\end{array}$ & $\begin{array}{l}\text { - Staphylococcus aureus } 33.6 \% \\
\text { ( } 42 \% \text { methicillin-sensitive) } \\
\text { - Enterococcus spp. } 10.7 \% \\
\text { - Viridans group streptococci } \\
9.8 \%\end{array}$ \\
\hline Gram-negative aerobes $17.1 \%$ & Gram-negative aerobes $37.5 \%$ \\
\hline $\begin{array}{l}\text { - Enterobacteriaceae } 10.8 \% \\
\text { - Klebseilla spp4.2\% } \\
\text { - Pseudomonas spp. } 3 \%\end{array}$ & $\begin{array}{l}\text { - Enterobacteriaceae } 17.8 \% \\
\text { - Pseudomonas spp. } 8.9 \% \\
\text { - Klebsiella spp. } 7.6 \%\end{array}$ \\
\hline Anaerobes $17.1 \%$ & Anaerobes $11 \%$ \\
\hline
\end{tabular}

Note: Data from Hassan et al. ${ }^{27}$

important to note that the incidence of anaerobic microorganisms quoted in Table 1 probably underestimates the true burden, due to issues with standard methods of culture. With molecular techniques, $70 \%$ of samples of pleural fluid with identifiable organisms show anaerobic bacteria. ${ }^{38}$ This mandates ensuring anaerobic coverage in empirical antibiotic regimens for treating pleural infection.

The more common isolation of gut bacteria in HA pleural infection is probably related to the frequency of neurological conditions impairing swallowing and/or consciousness level increasing the risk of aspiration. ${ }^{36}$

Fungi are uncommon causes of pleural infection and represent $3 \%$ of isolated microbes. ${ }^{27}$ Fungal infections tend to occur in patients with underlying immunocompromising conditions, and the commonest isolated are Candida spp. ${ }^{39}$

\section{Diagnosis}

\section{Clinical Assessment}

Clinical presentation in patients with pleural infection is both non-specific and variable, thus requiring a high index of suspicion. Broadly, presentations can be split into two groups. The first involves predominantly younger individuals with fewer comorbidities who may present with acute symptoms of respiratory infection: shortness of breath, pleuritic chest pain, fever, rigors with or without cough, and sputum production. A second group of individuals with immunocompromise, perhaps due to alcohol intake, diabetes, intravenous drug use, or frailty, may present in a more insidious fashion with weight loss, loss of appetite, malaise, and anemia. Among the latter group, aspiration and poor oral hygiene are being increasingly recognized as important risk factors, and an examination of the oral cavity and swallowing assessment should be routinely undertaken.

Failure to improve despite appropriate treatment in individuals being treated for pneumonia should be the first prompt to perform chest radiography or ultrasound to look for an associated effusion. The presence of a pleural effusion accompanied by infective symptoms should never be assumed to be an uncomplicated parapneumonic effusion, as this often leads to delayed diagnosis with poorer outcomes. ${ }^{5}$ Sampling of pleural fluid is always recommended to confirm pleural infection, provided the effusion is large enough to allow safe needle aspiration.

\section{Imaging}

\section{Chest Radiography}

Plain radiographs are usually the first line of investigation for patients with suspected pleural infection presenting with relevant respiratory symptoms. ${ }^{1}$ Despite their relatively modest sensitivity in characterizing pleural fluid collections, plain radiographs serve as an appropriate initial screening tool for pleural infections and other underlying or alternative parenchymal pathologies that could be responsible for the presenting symptoms. The infected pleural fluid tends to loculate, and thus chest radiography typically shows non-free flowing effusion (Figure 1A). For instance, the presence of the "D sign" suggests the diagnosis in the correct clinical setting (Figure 1B). ${ }^{40}$ It should be noted that chest radiography misses $>10 \%$ of significant parapneumonic effusions (ie, $\geq 10 \mathrm{~mm}$ in depth), particularly in the setting of a lower-lobe parenchymal consolidation. ${ }^{41}$

\section{Computed Tomography}

Computed tomography (CT) scanning offers an excellent rapid review of pleural anatomy and the extent of any infection. This proves to be important in cases where adequate drainage has not been achieved in a timely manner. The use of intravenous contrast with image acquisition after $60-90$ seconds (the portal venous phase) allows better delineation of pleural, parenchymal, and mediastinal pathologies. The split-pleura sign, caused by the collection of fluid between thickened visceral and parietal pleural layers, is highly suggestive of empyema (Figure 2A). ${ }^{42}$ Other CT findings suggestive of complicated pleural 

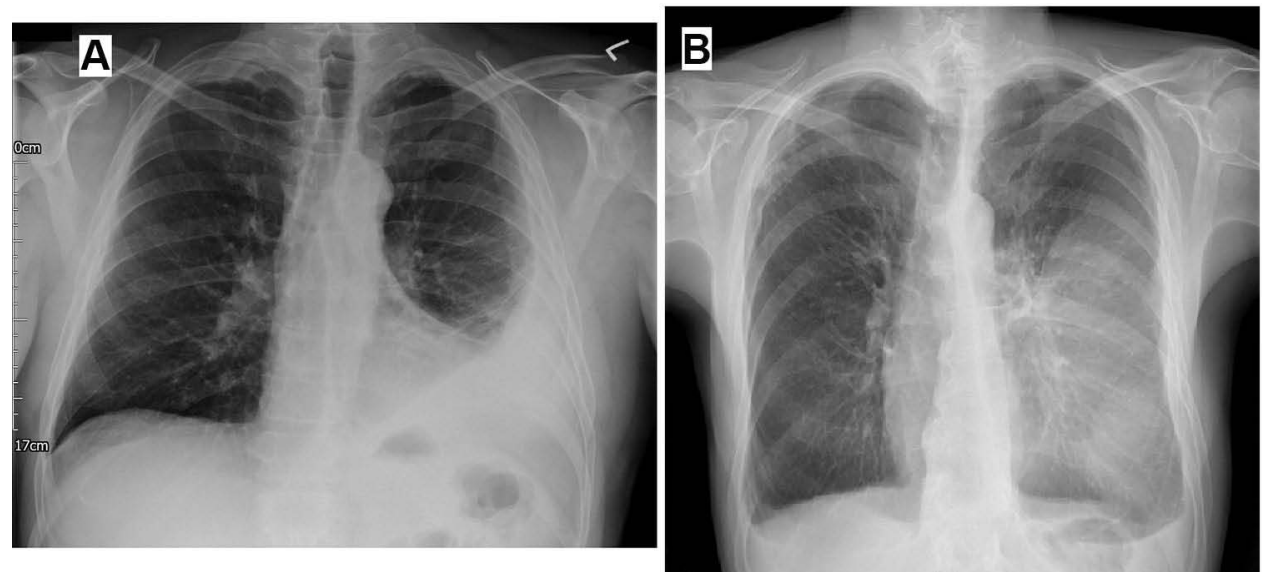

Figure I (A) Chest radiograph shows a left-side partially loculated pleural effusion. (B) Chest radiograph shows the D sign at the left hemithorax, indicating a laterally loculated pleural effusion.

effusion include contrast enhancement of thickened parietal pleura (Figure 2B), enhancing hypertrophied extrapleural fat (Figure 2C), air foci within the fluid (Figure 2A and $\mathrm{C}$ ), and an estimated fluid volume
$>400 \mathrm{~mL}$ (Figure 2A). A scoring model comprising these last CT radiological signs was found to be accurate at predicting the need for fluid drainage. ${ }^{43}$ However, CT does not offer optimal sensitivity for detecting pleural

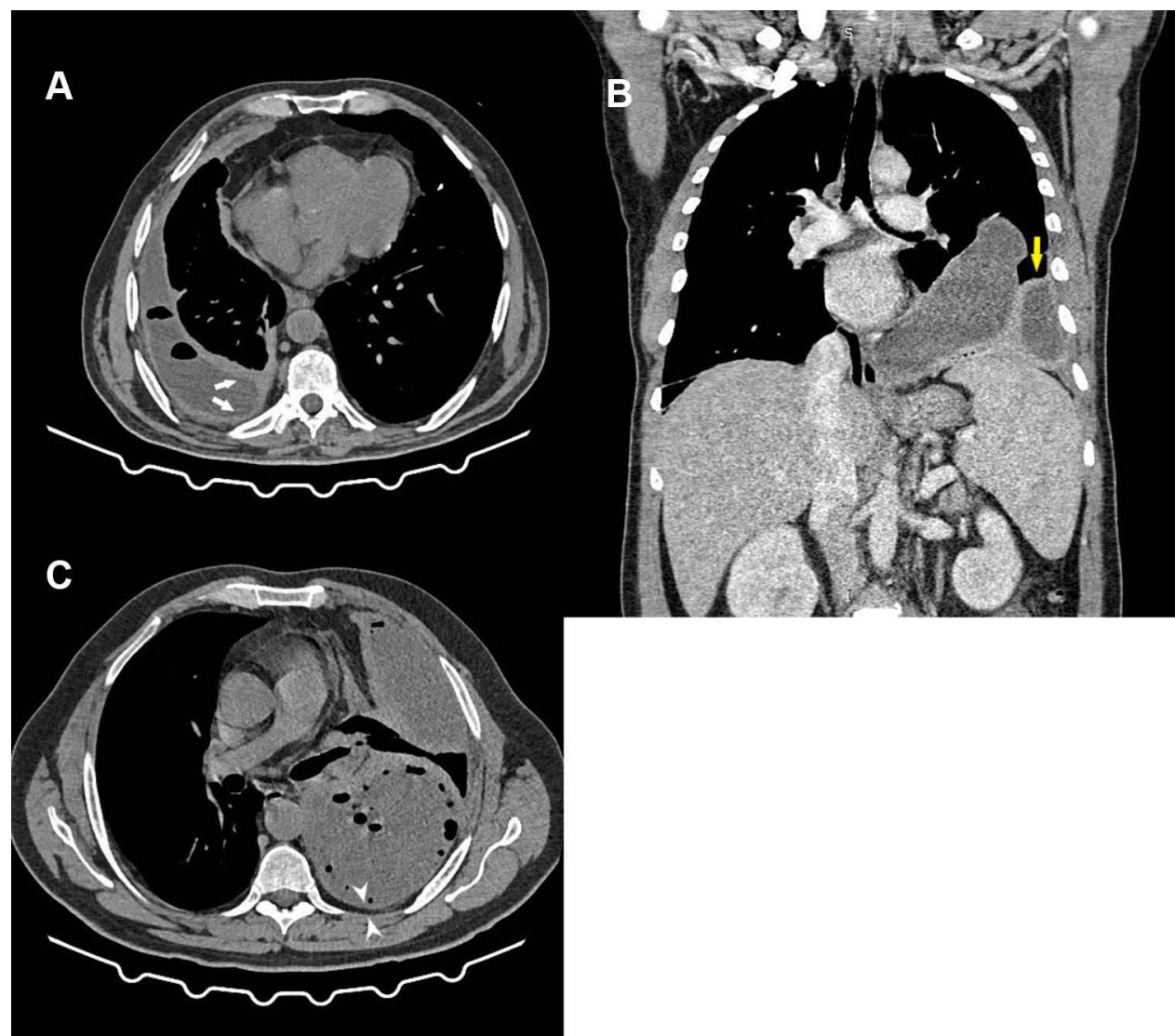

Figure 2 Thoracic computed tomography demonstrating features of pleural infection. (A) Axial cut in mediastinal window showing a right-side pleural effusion with multiple air foci and "split pleura" (white arrows). (B) After intravenous contrast injection (coronal reconstruction in mediastinal window), showing left-side multiloculated empyema with enhancing pleural thickening (yellow arrow). (C) Axial cut in mediastinal window showing a left-side multiloculated pleural empyema with multiple air foci and posterior parietal pleural thickening and extrapleural fat hypertrophy (arrowheads). 
septations, ${ }^{44}$ and thus ultrasound guidance is crucial for guiding diagnostic and therapeutic interventions in pleural infections.

\section{Thoracic Ultrasound}

A thoracic ultrasound examination is currently considered a sine qua non for safe and efficient management of pleural infection. It is cost-effective, radiation-free, readily available at the bedside, and offers the possibility of real-time guided intervention. Despite pleural effusion being reported to affect around $20 \%$ of pneumonia patients, the higher ultrasound sensitivity could increase this figure to $>50 \%$ of cases. ${ }^{45}$ The ultrasonographic images allow probing into the characteristics of the fluid collection in terms of location, organization, and echogenicity, thus giving more insight as to the underlying nature of the effusion. Highly echogenic pleural collections usually represent pus, and the ultrasound appearance is particularly predictive of aspirating purulent fluid in the presence of coarse echogenic "gas bubbles" (Figure 3A), which can be seen floating inside the effusion. ${ }^{46}$ The presence of septations on ultrasound (Figure 3B) is a feature of pleural infection and one of the criteria for differentiating simple from complicated parapneumonic effusion as per the American College of Chest Physicians guidelines on parapneumonic effusion. ${ }^{47}$ Recently, the use of the quantitative echogenicity index has been shown to predict the degree of pleural inflammation, which might aid in guiding management. ${ }^{48}$ Thoracic ultrasound is particularly helpful in identifying the best location for drain insertion. ${ }^{45}$

\section{Pleural Fluid}

The aspiration of pus confirms the diagnosis of pleural infection and does not require any further biochemical analysis. Pleural fluid $\mathrm{pH}$ remains the most sensitive surrogate of pleural infection in nonpurulent collections, ${ }^{49}$ with the caveat that variations in measurement or false readings may occur due to contamination with local anesthetic, delay in analysis, or the presence of air bubbles in the fluid sample. In addition, it is acknowledged that individual locules within a multiloculated effusion can produce diagnostically significant variations in $\mathrm{pH}^{50}$ and infection with certain organisms (particularly Proteus spp.) may result in increased pleural fluid $\mathrm{pH}^{51}$ It is accepted that pleural fluid $\mathrm{pH}<7.2$ is an indication for chest-tube drainage. Pleural fluid glucose can be used to support a diagnosis of pleural infection where $\mathrm{pH}$ sampling is inaccurate or not feasible. ${ }^{52}$ Pleural fluid glucose $<40 \mathrm{mg} / \mathrm{dL}$ alongside pleural LDH $>1,000 \mathrm{IU} / \mathrm{L}$ (ie, more than three times the upper normal limit for serum $\mathrm{LDH}$ ) is suggestive of pleural infection. ${ }^{53}$ In nonpurulent effusions, pleural fluid CRP $>100 \mathrm{mg} / \mathrm{L}$ may contribute to the diagnosis of complicated parapneumonic effusions, but this is not routinely measured. ${ }^{54,55}$

Pleural fluid should always be sent for microbiological analysis at the time of sampling in both universal containers and Bactec blood-culture bottles, as the latter have been shown to increase diagnostic yield by up to $20 \%{ }^{56}$ In the correct clinical setting and if contamination is reasonably ruled out, a positive Gram stain or culture confirms the diagnosis of pleural infection independent of biochemical analyses, and either of these reflects the need to progress to chest-tube drainage. Blood-culture

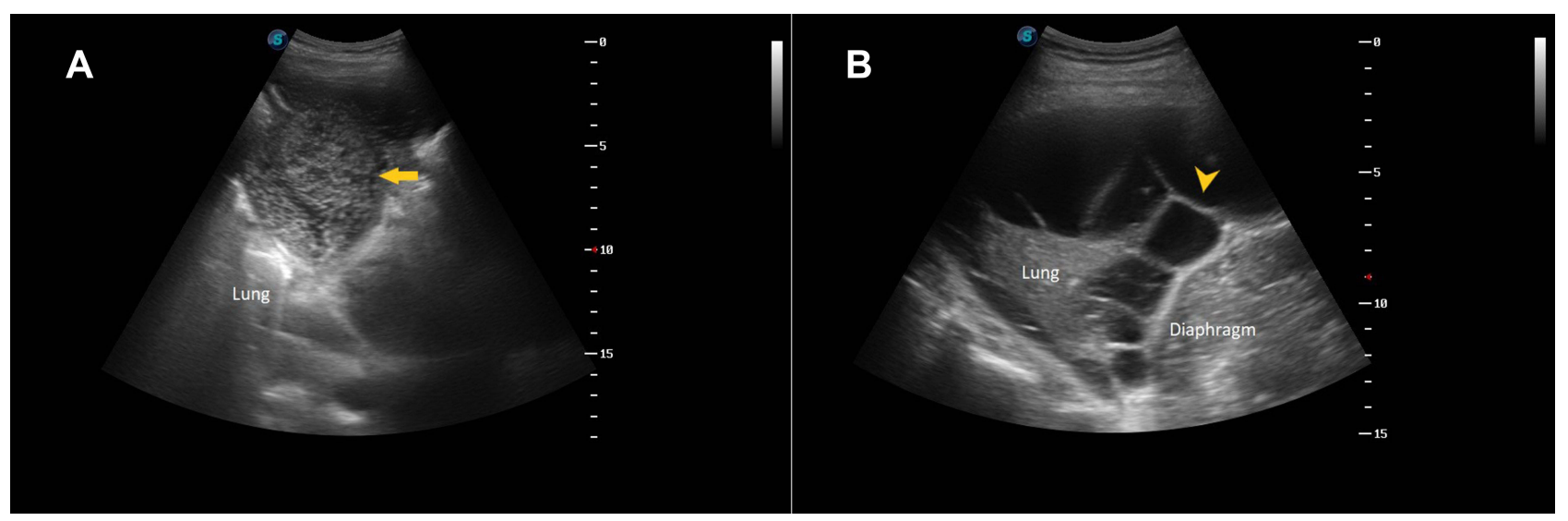

Figure 3 (A) Ultrasound showing left-side lung consolidation and heavily echogenic effusion (arrow) which turned out to be pus on thoracentesis. (B) Ultrasound showing multiple septations (arrowhead) in the pleural collection with underlying lung consolidation just above the left hemidiaphragm. 
samples were the only positive microbiological source in $12 \%$ of pleural infection cases in previous trial analyses, ${ }^{1}$ and ought to be undertaken as routine care. A pilot study upheld the feasibility of undertaking parietal pleura biopsy with the use of a cutting needle at the time of chest-drain insertion to undergo microbiological testing, which increased the microbiological yield by $25 \%$ compared to standard practice. ${ }^{26}$ Further multicenter studies are being planned to confirm the benefit from this additional intervention.

Such biomarkers as serum procalcitonin have not been shown to be superior to established biomarkers ofinfection, including raised white blood-cell count and $\mathrm{CRP},{ }^{57}$ they may have a role in differentiating pleural infection from inflammatory malignancy where pleural fluid biochemistry may be similar. ${ }^{58}$

\section{Nucleic Acid Tests}

Nucleic acid-amplification tests have proved more sensitive in establishing the microbial cause of pleural infection. ${ }^{28,59}$ The technique involves identifying the $16 \mathrm{~S}$ rRNA gene (universally found in bacteria with minute species-specific differences) or other related genes ${ }^{38}$ in pleural fluid samples. ${ }^{59}$ Despite being more sensitive than standard cultures, the initial use of this technique involved complex multistep processes to identify the exact causative organism. ${ }^{28,29,59}$ With the advent of highthroughput DNA sequencing, the process can now be completed using a single assay with high sensitivity. ${ }^{38}$ However, such techniques are prohibitively costly and the equipment and expertise to perform them are unlikely to be widely available, which makes them more of a research tool than a clinical test used at scale. More promising applications for clinical use are the multiplex PCR-type assays: using a single sample, these can detect any of a set of multiple microbes (bacteria, viruses, or fungi). These assays have proved highly sensitive, with information directly affecting the care of patients with CAP. ${ }^{60}$ Digital droplet PCR, which employs similar methodology to multiplex PCR, has been successfully used to identify bacteria in pleural fluid, with sensitivity higher than standard cultures. ${ }^{61}$ Moreover, commercially available multiplex-PCR methods used in $\mathrm{CAP}^{62}$ have proved more sensitive to conventional cultures in the bacteriological diagnosis of pleural infection. Multiplex-type techniques carry the advantages of utilizing widely available equipment and being relatively inexpensive. They have short turnaround times (a few hours) and are particularly sensitive for polymicrobial infection ${ }^{61}$ and in patients who have started antibiotics. ${ }^{62}$ A pleural infection-specific multiplex-PCR panel that incorporates genetic sequence of anaerobes commonly implicated in pleural infection may transform the diagnosis and treatment decisions in pleural infection as this technology becomes more readily available at bench and bedside.

It is noteworthy that nucleic acid tests are not able to provide information on the pattern of antibiotic sensitivity for identified pathogens. Another important challenge with interpreting positive results is differentiating between true infection and potential contamination of samples.

\section{Treatment}

\section{General Measures}

Prompt drainage of infected pleural collection together with timely and appropriate antibiotic therapy remain the core foundations of treatment, aiming to achieve early sepsis control. Given the catabolic state associated with pleural infection, other key supportive measures include ensuring adequate nutritional intake and addressing thromboprophylaxis alongside other best-practice treatment of sepsis.

\section{Antibiotic Therapy}

Empirical antibiotic choices governed by local prescribing policies and taking into consideration both the prevalence of local organisms and the setting in which infection has been acquired should be initiated as soon as infection is suspected. Chosen agents should cover both aerobic and anaerobic organisms, as described earlier, until results of microbiological tests are available allowing de-escalation /modification as appropriate. Antibiotics that are known to have good penetration into the pleural space include penicillins, metronidazole, and cephalosporins, followed by vancomycin and clindamycin. ${ }^{63}$ Aminoglycosides have poor penetration into the pleura and are inactivated by the acidic medium of the infected pleural space. ${ }^{64}$

In CA pleural infection, suitable antibiotic regimens include either parenteral second- or third-generation cephalosporin (eg, ceftriaxone) combined with metronidazole for anaerobic cover or a $\beta$-lactam/ $\beta$-lactamase inhibitor combination (eg, amoxicillin-clavulanic acid or ampicillin-sulbactam) taken as a sole agent. In patients with penicillin allergy, moxifloxacin used as a single agent or a combination of levofloxacin and metronidazole are appropriate alternatives. In HA pleural infection, 
antipseudomonal antibiotics with anaerobic coverage are required. Suitable regimens include cefepime-metronidazole, piperacillin-tazobactam, or a carbapenem. Additionally, covering for $S$. aureus in the form of vancomycin or linezolid should be considered in HA infection, particularly when a patient is already known to be colonized by this organism. ${ }^{65}$

The optimal timing as to when to transfer from intravenous to oral antibiotics has not yet been defined, but pragmatically would be governed by clinical response (defervescence) and biochemical parameters (fall in white blood-cell count and CRP), which are likely to have occurred at the point when the chest tube is ready to be removed. A consensus opinion as to length of antibiotic treatment is lacking. However, antibiotics are often continued for at least 4 weeks, ${ }^{1}$ inferred from the management of lung abscess. A randomized controlled trial (RCT) on patients with complicated parapneumonic effusion who were stable after 2 weeks of antibiotic treatment reported that a 2 -week course was probably no inferior to a 3-week course in terms of treatment failures. ${ }^{66}$ However, this study did not include patients with primary pleural infection and was unable to recruit the total planned number of participants.

\section{Intrapleural Antibiotics}

To circumvent the significant issue of poor antibiotic penetration into the pleural space, consideration has been given to direct instillation of antibiotics into the pleural space, akin to surgical practice in the management of postpneumonectomy empyema. However, outside this context, the evidence is sparse and limited to retrospective case series. ${ }^{67,68}$ One animal study has examined the use of a novel antibiotic-eluting intrapleural pigtail catheter. This was coated with electrospun nanofibers used for sustained release of bactericidal concentrations of penicillin in the pleural space. Their positive results suggest this is a promising area for future human research. ${ }^{69}$

\section{Chest-Tube Drainage}

Prompt evacuation of infected fluid remains a priority, since its delay correlates with mortality at 90 days. ${ }^{5}$ As a prospective study of chest-drain size is yet to be undertaken, the best-available evidence comes from a post hoc analysis of multicenter RCT data demonstrating that a smaller-bore chest drain $(\leq 14 \mathrm{Fr})$ was not associated with increased mortality or need for thoracic surgery at 12 months. This effect was shown to be independent of the purulence of pleural fluid, thereby refuting the commonly held belief that "bigger is better," albeit within the limitations of a post hoc analysis. ${ }^{70}$ Smaller-bore chest tubes result in significantly lower pain scores, ${ }^{70}$ and in combination with frequent saline flushes (eg, $30 \mathrm{~mL}$ three times daily) are thus recommended in the first instance.

Although failure to improve despite standard care is known to complicate the disease course in a third of patients, there are no clearly defined objective criteria outlining the point at which escalation of treatment is required. Broadly, patients should be considered to have failed standard care if after 2-3 days of treatment, they have ongoing pyrexia or failure of CRP to fall $>50 \%$ with persistent pleural collection.

\section{Intrapleural Enzyme Therapy}

Preventing progression from the fibropurulent stage to the later organizing stage with development of a solid fibrous pleural peel is important, given the physiological changes that occur in the pleural space during infection. Publication of the results of the MIST-2 RCT in 2011 created a paradigm shift in the use of intrapleural fibrinolytics. ${ }^{71}$ The trial found that the combination of an intrapleural tissue plasminogen activator (tPA) and deoxyribonuclease (DNase) augmented drainage of infected fluid, improving the appearance of chest radiographs (primary outcome), with a strong signal toward benefit in key clinical outcomes, including length of stay and surgical referral rates (secondary outcomes). ${ }^{71}$ tPA aids the division of intrapleural septations as a direct fibrinolytic agent, while DNase causes cleavage of free DNA, reducing fluid viscosity and further permitting drainage of fluid by the adjunctive tPA. Furthermore, it has been hypothesized that DNase may interfere with the formation of biofilms, which contain both fibrin and DNA as constituent parts, enhancing the effect of antibiotics. ${ }^{72,73}$ Similarly to other fibrinolytic agents, tPA has been shown to increase pleural fluid output, thereby triggering a therapeutic lavage effect within the infected pleural space. ${ }^{74,75}$

The limited number of patients in the combination arm $(n=52)$ meant that the results of the MIST-2 RCT required replication on a larger scale before routine use can be widely recommended as standard of care, although there are now $>600$ patients described in the literature who have been safely and successfully treated with the MIST-2 regimen, including large case series. ${ }^{76}$ To date, combination intrapleural enzyme therapy (IET) is reserved for patients who fail standard care and are poor surgical 
candidates due to frailty and comorbidity. This intervention may also be useful in settings where access to surgery is limited or where delay is anticipated.

Streptokinase, a cheaper agent than the MIST-2 regimen, has shown benefit in terms of radiological resolution of pleural infection and need for surgery in small-scale clinical trials, ${ }^{77,78}$ but this benefit was not replicated in the large MIST-1 trial. ${ }^{79}$ However, streptokinase continues to be used as a fibrinolytic agent in complex pleural infection in parts of the world where resources are limited.

\section{Safety Profile}

Questions are often raised as to the safety of IET. Potential side effects are known, and include pleural hemorrhage, pleuritic pain after drug administration, and fever. Despite the results of MIST-2 showing no statistically significant increase in bleeding between intrapleural tPA and placebo, bleeding risk continues to be a subject of concern among some clinicians. There have been a few isolated case reports of both systemic and local hemorrhage, but the majority of published studies have reported no increase in bleeding complications. A retrospective case series did propose a link between increased risk of intrapleural hemorrhage and concurrent use of therapeutic-dose anticoagulation, and this was stipulated to be due to a local synergistic effect at the pleural surface. This increased risk was not seen in patients on prophylactic-dose anticoagulation alone. ${ }^{80}$ As a practice point, the authors do not recommend suspending prophylactic-dose anticoagulation, due to the increased risk of venous thromboembolism in patients with pleural infection, and not to be alarmed by the "red" discoloration of pleural fluid, which is expected to occur from lysis of fibrinous septations.

\section{Dosing and Administration}

The current recommended regimen by the authors is intrapleural injection of $10 \mathrm{~mL}$ tPA followed by a $10 \mathrm{~mL}$ sodium chloride $0.9 \%$ flush, then $5 \mathrm{mg}$ DNase, a further $10 \mathrm{~mL}$ sodium chloride $0.9 \%$ flush in a single sitting, and then clamping for 1 hour before allowing free drainage. This is repeated at 12-hourly intervals up to a maximum of six doses. Concurrent administration of the two medications appears to be an equally effective regimen of dosing. ${ }^{81,82}$ Recent data have suggested that halving the dose of tPA to $5 \mathrm{mg}$ is safe and effective. ${ }^{83}$ While this reduced dose has not been tested in the context of an RCT, it is an appropriate alternative strategy in patients deemed to be at increased bleeding risk.

\section{Surgical Intervention}

The final organizing stage of pleural infection is characterized by fibroblast proliferation and the formation of a solid fibrous pleural peel that can potentially encase the lung parenchyma, preventing lung reexpansion and resulting in impairment of lung function. Medical therapies, including IET, are likely to fail at this stage. It is estimated that surgical intervention will be warranted for the $15 \%-20 \%$ of individuals with pleural infection who do not improve with medical management. Surgery is also indicated in the setting of extensive pleural thickening that impedes reduction of the pleural space and eradication of the infection. ${ }^{1}$

Surgical intervention includes both video-assisted thoracoscopic surgery (VATS) and thoracotomy and drainage, the former being used increasingly as a first-line intervention due to its minimally invasive nature and the advantages this brings with respect to length of inpatient stay, complication rate, and postoperative morbidity. ${ }^{84}$ Both interventions encompass the debridement and evacuation of infected material. More extensive decortication is required where a thickened visceral pleural peel has formed to allow for lung reexpansion.

Suitability for surgical intervention, given the increasingly older population being treated for pleural infection, remains problematic. Both VATS and thoracotomy require single-lung ventilation, and there remains a subset of patients in whom mortality from pleural infection at the time of referral is greater than the mortality associated with surgical intervention. This is where personalized riskstratification scores, such as RAPID, may have a valid role (see following). It is noteworthy that some centers have the expertise to deliver VATS via a single port and under sedation without the requirement for intubation or singlelung ventilation. ${ }^{85,86} \mathrm{Up}$ to partial decortication can be performed during an "awake" VATS, but the availability of this technique remains limited and its efficacy versus the standard approach is yet to be tested. ${ }^{85}$

The use of surgical intervention as a first-line treatment has been justified in a number of countries on the basis of the reduction in length of inpatient stay and improved clinical outcome. ${ }^{87,88}$ However, there remains a lack of robust data justifying this practice, with those RCTs addressing this question being underpowered, with evidence of selection bias, lacking standardized criteria for surgery, and involving relatively young populations. ${ }^{89}$ Critical questions as to the most appropriate time to refer for surgical intervention and the group of individuals that 
would benefit from this the most due to the likelihood of failure of conventional first-line treatment are yet to be answered. Head-to-head RCTs involving early randomization of patients to surgery and IET are currently under way. It is worth noting that the precise surgical intervention required is not clearly defined and practice remains variable according to individual surgical preference.

\section{Other Interventions}

Medical Thoracoscopy. The increasing practice of physician-led thoracoscopy has prompted interest into its role in pleural infection. In theory, the ability to perform drainage, mechanically disrupt septations, and insert a chest tube under direct vision would be advantageous. A meta-analysis of eight observational studies found a pooled success rate of $85 \%$ when medical thoracoscopy was used as a first-line treatment for pleural infection..$^{90} \mathrm{~A}$ small RCT comparing medical thoracoscopy with IET in patients with incomplete drainage 24 hours after chest-tube insertion concluded that using medical thoracoscopy leads to shorter hospital stays (3.5 vs 6 days for IET) with no between-group differences in rates of treatment failure or mortality. ${ }^{91}$ Despite experiences reported in the literature, ${ }^{92-94}$ this treatment has not yet made its way into international guidelines. ${ }^{1,65}$

Pleural Irrigation. Pleural irrigation, the practice of instilling a large volume of liquid into the pleural space and allowing free drainage, builds on the concept of a therapeutic lavage effect. This has been examined in a single-center RCT, where saline pleural irrigation (three times daily for 3 days) plus standard care showed a significantly smaller collection on CT imaging compared to standard care alone. Few individuals required referral for surgery in the irrigation arm. ${ }^{95}$ An RCT is required to assess the effects of this practice and the possible role it may play in individuals considered too high-risk for surgery or in those who have a contraindication to the use of IET. A retrospective study has shown that repeated intrapleural flushes of saline into the pleural cavity followed by manual aspiration until the aspirated fluid is clear (average total lavage volume $200-300 \mathrm{~mL}$ ) reduced time to chest-tube removal and number of IET doses needed. ${ }^{96}$

Pleural irrigation with antiseptic solution is used in the management of chronic empyema undergoing open drainage. ${ }^{97}$ Antiseptic irrigation has also reportedly been used in the management of acute pediatric empyema. ${ }^{98}$ Whether pleural irrigation with antiseptic solution can improve outcomes in adult acute pleural infection is another intervention to be explored in future research.

Repeated Pleural Aspiration. The possibility of managing a small subset of pleural infection patients, who are likely to be young, with no overt markers of sepsis and a unilocular effusion in an ambulatory setting with antibiotics and repeated thoracentesis remains an attractive proposition. There are data to suggest that in selected patients, this approach may be a reasonable alternative to chest-tube drainage. ${ }^{99,100}$ However, this approach remains exploratory, due to a lack of prospective data examining its efficacy against the current standard of practice.

\section{Outpatient Follow-Up}

Based on the authors' experience, an initial follow-up chest radiograph or ultrasound and review of inflammatory markers at approximately 2 weeks postdischarge is important to identify early treatment failure, which would be suggested by rising inflammatory markers and recurrence of pleural collection. Where possible, these patients are better seen in a dedicated pleural clinic where simultaneous thoracic ultrasound assessment can be carried out. Further review at 4-6 weeks after completion of antibiotic therapy is also routinely recommended. At this point, most patients can be discharged and will have begun to resume their usual daily activities and feel back to baseline. A small number of individuals will require longer-term follow-up due to slow recovery or complications of their initial infection/management. Of the more common longterm complications are residual pleuritic pain and residual pleural thickening, occasionally causing restrictive pulmonary function and chronic breathlessness. Due to limited follow-up in studies, the long-term outcomes/recovery in pleural infection have not been well characterized.

\section{Outcomes of Pleural Infection}

Prompt diagnosis and initiation of appropriate treatment modalities, namely drainage and antibiotic therapy, are of paramount importance in improving patien' outcomes. ${ }^{101,102}$ A recent systematic review has shown that the median length of hospital stay was 19 days (IQR 13-27). ${ }^{17}$ Length of hospital stay has been shown to be affected by timely diagnosis of pleural infections, which underscores the importance of rapidly obtaining the first sample. ${ }^{103}$ A non-Streptococcus milleri pleural infection has been associated with prolonged hospital stay. ${ }^{104} \mathrm{On}$ a similar note, mortality at 1 year was higher among the MIST-1 cohort with $S$. aureus or mixed aerobic 
infections. $^{28}$ HA infections are associated with higher mortality rates. ${ }^{28,105}$ Data from population-based studies have shown that mortality from pleural infection tends to fall in the range of $10 \%-30 \%$, with differences in rates reported dependent on timelines used and demographics of studied patients. ${ }^{1,8,12,36,106,107}$

It was observed with long-term follow-up that even after successful treatment of pleural infection, patients would still suffer from more health-care utilization, higher rates of hospitalization, longer in-hospital stays, and worse mortality. This probably reflects the multimorbidity effects in an aging population in which the incidence of pleural infection could be consequential. ${ }^{17,20,108}$ It should be noted, however, that this demographic characterization applies to reports mostly from high-income countries, with relatively insufficient evidence of a similar picture in lower-income countries.

\section{Risk Stratification}

Recognition of the significant morbidity and mortality associated with pleural infection has led to efforts to identify individual risk factors that are associated with poor outcomes and develop validated risk-prediction scores to enable early identification of high-risk patients, potentially guiding appropriate subgroups toward earlier aggressive treatment. Mortality rates at 30 days of up to $10 \%$ have been reported. ${ }^{106}$ Validated risk scores for both sepsis (quick sepsis-related organ-failure assessment, qSOFA) and CAP (CURB-65) do not predict the development of pleural infection. ${ }^{23}$

Individual patient risk factors that have been associated with poor outcomes include age $>65$ years, cirrhosis and a past or present malignancy. ${ }^{109}$ Factors that have been associated with poor outcomes, such as the sonographic appearance of a complex septated effusion ${ }^{110}$ and pleural fluid purulence, ${ }^{108}$ have not been borne out in large multicenter trials. The Charlson comorbidity index was found to provide reasonable prediction of mortality risk (AUC 0.753). However, owing to the retrospective nature of the study and the lack of data on some confounding factors, these results need to be prospectively validated in other cohorts. ${ }^{111}$

To date, the only outcome-prediction score that has been prospectively studied and externally validated is the RAPID score (Table 2). ${ }^{9,10}$ This was created using the two largest multicenter pleural infection studies to date (MIST1 and MIST-2) ${ }^{71,79}$ to create predictors that are clinically accessible at baseline: urea (renal), age, nature of pleural fluid (purulence), infection source (I), and serum albumin
Table 2 Variables that make up the RAPID score used for outcome prediction in adult pleural infection

\begin{tabular}{|l|l|}
\hline & Score \\
\hline $\begin{array}{l}\text { Renal function (blood urea nitrogen) } \\
<14 \mathrm{mg} / \mathrm{dL} \\
14-23 \mathrm{mg} / \mathrm{dL} \\
>23 \mathrm{mg} / \mathrm{dL}\end{array}$ & 0 \\
\hline $\begin{array}{l}\text { Age } \\
<50 \text { years } \\
50-70 \text { years } \\
>70 \text { years }\end{array}$ & 2 \\
\hline $\begin{array}{l}\text { Purulence of pleural fluid } \\
\text { Purulent } \\
\text { Non-purulent }\end{array}$ & 0 \\
\hline $\begin{array}{l}\text { Infection setting } \\
\text { Community-acquired } \\
\text { Hospital-acquired }\end{array}$ & $\mathrm{I}$ \\
\hline $\begin{array}{l}\text { Dietary factors (serum albumin) } \\
\geq 2.7 \text { gm/dL } \\
<2.7 \text { gm/dL }\end{array}$ & 0 \\
\hline
\end{tabular}

Notes: Risk categories: score 0-2 low risk; score 3-4 medium risk; score 5-7 high risk. Data from Rahman et al. ${ }^{9}$

(dietary). Together, these stratify adults with pleural infection according to mortality at 3 months and association with length of hospital stay. ${ }^{10}$ It currently remains undefined as to how to use this risk score to guide clinical decision-making, particularly with respect to escalation of intervention, and further studies triaging patients to varying levels of management based on the RAPID score are required. ${ }^{112}$ It is worth noting that the validity of this score is yet to be confirmed for predicting outcomes in patients from lower-income countries, who tend to be younger.

\section{Knowledge Gaps and Future Directions}

Despite continuous progress in knowledge about and management of pleural infection, there remains substantial room for improvement, and many questions are yet to be answered. The use of a validated risk-prediction model (ie, RAPID score) to inform management appears to be the ultimate aim for developing such a model. Current research is looking into using this score to choose patients who could be suitable for shorter outpatient courses of antibiotics once their condition has stabilized (NCT04615286), given the lack of high-quality evidence 
to support the current recommendation to prescribe antibiotics for 4 weeks or longer. The role of upfront invasive techniques, such as medical thoracoscopy or surgery, needs better defining through head-to-head clinical trials. The MIST-3 RCT is currently examining the feasibility of randomizing patients with pleural infection to upfront surgery, early IET, or standard care. Another management question that has not been addressed is the role of sonographic stratification to different treatment modalities and how the sonographic picture at baseline correlates with outcomes. Further work needs to be done before molecular tests can be used in routine clinical practice to identify offending pathogens in pleural infection, and this will probably involve studies to develop a pleural infection-specific multiplextype assay. Finally, the role of intrapleural therapy in pleural infection, such as antibiotic-eluting chest tubes and antiseptic or saline pleural irrigation, is a potential area of future research.

\section{Disclosure}

The authors declare no conflicts of interest for this work.

\section{References}

1. Davies HE, Davies RJO, Davies CWH, on behalf of the BTS Pleural Disease Guideline Group. Management of pleural infection in adults: british Thoracic Society pleural disease guideline 2010. Thorax. 2010;65(Suppl 2):ii41-ii53. doi:10.1136/thx.2010.137000

2. Peters RM. Empyema thoracis: historical perspective. Ann Thorac Surg. 1989;48(2):306-308. doi:10.1016/0003-4975(89)90100-8

3. Meyer JA. Gotthard Bülau and closed water-seal drainage for empyema, 1875-1891. Ann Thorac Surg. 1989;48(4):597-599. doi:10.1016/s0003-4975(10)66876-2

4. Bender JM, Ampofo K, Sheng X, Pavia AT, Cannon-Albright L, Byington CL. Parapneumonic Empyema Deaths during Past Century, Utah. Emerg Infect Dis. 2009;15(1):44-48. doi:10.3201/ eid1501.080618

5. Meyer $\mathrm{CN}$, Armbruster $\mathrm{K}$, Kemp $\mathrm{M}$, et al. Pleural infection: a retrospective study of clinical outcome and the correlation to known etiology, co-morbidity and treatment factors. BMC Pulm Med. 2018;18(1):160. doi:10.1186/s12890-018-0726-1

6. Gupta I, Eid SM, Gillaspie EA, Broderick S, Shafiq M. Epidemiologic Trends in Pleural Infection. A Nationwide Analysis. Annals ATS. 2021;18(3):452-459. doi:10.1513/AnnalsATS.202001-075OC

7. Bedawi EO, Hassan M, McCracken D, Rahman NM. Pleural infection: a closer look at the etiopathogenesis, microbiology and role of antibiotics. Expert Rev Respir Med. 2019;13(4):337-347. doi:10.1080/17476348.2019.1578212

8. Brims F, Popowicz N, Rosenstengel A, et al. Bacteriology and clinical outcomes of patients with culture-positive pleural infection in Western Australia: a 6-year analysis: empyema in Western Australia 2006-2011. Respirology. 2019;24(2):171-178. doi:10.1111/resp.13395

9. Rahman NM, Kahan BC, Miller RF, Gleeson FV, Nunn AJ, Maskell NA. A clinical score (RAPID) to identify those at risk for poor outcome at presentation in patients with pleural infection. Chest. 2014;145(4):848-855. doi:10.1378/chest.13-1558
10. Corcoran JP, Psallidas I, Gerry S, et al. Prospective validation of the RAPID clinical risk prediction score in adult patients with pleural infection: the PILOT study. Eur Respir J. 2020;56 (5):2000130. doi:10.1183/13993003.00130-2020

11. Nayak R, Brogly SB, Lajkosz K, Lougheed MD, Petsikas D. Two decades of thoracic empyema in Ontario, Canada. Chest. 2020;157(5):1114-1116. doi:10.1016/j.chest.2019.11.040

12. Grijalva CG, Zhu Y, Nuorti JP, Griffin MR. Emergence of parapneumonic empyema in the USA. Thorax. 2011;66(8):663-668. doi:10.1136/thx.2010.156406

13. Bobbio A, Bouam S, Frenkiel J, et al. Epidemiology and prognostic factors of pleural empyema. Thorax. 2021:thoraxjnl-2020215267. doi:10.1136/thoraxjnl-2020-215267.

14. Lehtomäki A, Nevalainen R, Ukkonen M, Nieminen J, Laurikka J, Khan J. Trends in the incidence, etiology, treatment, and outcomes of pleural infections in adults over a decade in a Finnish University Hospital. Scand J Surg. 2020;109 (2):127-132. doi:10.1177/1457496919832146

15. Shen H-N, Lu C-L, Li C-Y. Epidemiology of pleural infections in Taiwan from 1997 through 2008: pleural infections in Taiwan. Respirology. 2012;17(7):1086-1093. doi:10.1111/j.14401843.2012.02214.x

16. Mitchell MA, Deschner E, Dhaliwal I, Amjadi K, Chee A. Association of patient demographics and comorbidities with clinical outcomes in adults hospitalized for Empyema. Ann Am Thorac Soc. 2021;18(5):904-906. doi:10.1513/AnnalsATS.2020 08-1011RL

17. Cargill TN, Hassan M, Corcoran JP, et al. A systematic review of comorbidities and outcomes of adult patients with pleural infection. Eur Respir J. 2019. doi:10.1183/13993003.005412019

18. Wong D, Yap E. Pleural infection in a New Zealand centre: high incidence in Pacific people and RAPID score as a prognostic tool: pleural infection in New Zealand. Intern Med J. 2016;46 (6):703-709. doi:10.1111/imj.13087

19. Ahmed RA, Marrie TJ, Huang JQ. Thoracic empyema in patients with community-acquired pneumonia. Am J Med. 2006;119 (10):877-883. doi:10.1016/j.amjmed.2006.03.042

20. Lehtomäki AI, Nevalainen RM, Toikkanen VJ, et al. Pleural infection - an indicator of morbidity and increased burden on health care. Interact Cardiovasc Thorac Surg. 2020;31 (4):513-518. doi:10.1093/icvts/ivaa147

21. Schweigert M, Solymosi N, Dubecz A, et al. Surgery for parapneumonic pleural empyema--What influence does the rising prevalence of multimorbidity and advanced age has on the current outcome? Surgeon. 2016;14(2):69-75. doi:10.1016/j.surge.2014.05.002

22. Cohen E, Mahant S, Dell SD, et al. The long-term outcomes of pediatric pleural empyema: a prospective study. Arch Pediatr Adolesc Med. 2012;166(11):999-1004. doi:10.1001/archpedia trics.2012.1055

23. Chalmers JD, Singanayagam A, Murray MP, Scally C, Fawzi A, Hill AT. Risk factors for complicated parapneumonic effusion and empyema on presentation to hospital with community-acquired pneumonia. Thorax. 2009;64(7):592-597. doi:10.1136/thx.2008 .105080

24. Amaro R, Sellarés J, Riesco J, Cillloniz C, Abad E, Torres A. Late-breaking abstract: smoking is associated with higher incidence of parapneumonic effusion in community-acquired pneumonia. Eur Respir J. 2014;44(Suppl 58):P318.

25. Noppen M. Normal volume and cellular contents of pleural fluid. Curr Opin Pulm Med. 2001;7(4):180-182. doi:10.1097/ 00063198-200107000-00002

26. Psallidas I, Kanellakis NI, Bhatnagar R, et al. A pilot feasibility study in establishing the role of ultrasound-guided pleural biopsies in pleural infection (The AUDIO Study). Chest. 2018;154 (4):766-772. doi:10.1016/j.chest.2018.02.031 
27. Hassan M, Cargill T, Harriss E, et al. The microbiology of pleural infection in adults: a systematic review. Eur Respir J. 2019;54 (3):1900542. doi:10.1183/13993003.00542-2019

28. Maskell NA, Batt S, Hedley EL, Davies CWH, Gillespie SH, Davies RJO. The bacteriology of pleural infection by genetic and standard methods and its mortality significance. Am J Respir Crit Care Med. 2006;174(7):817-823. doi:10.1164/rccm.200601-074OC

29. Wrightson JM, Wray JA, Street TL, et al. Absence of atypical pathogens in pleural infection. Chest. 2015;148(3):e102-e103. doi:10.1378/chest.15-1130

30. Lisboa T, Waterer GW, Lee YCG. Pleural infection: changing bacteriology and its implications: pleural infection: changing bacteriology. Respirology. 2011;16(4):598-603. doi:10.1111/ j.1440-1843.2011.01964.x

31. Chen KY, Hsueh PR, Liaw YS, Yang PC, Luh KT. A 10-year experience with bacteriology of acute thoracic empyema: emphasis on Klebsiella pneumoniae in patients with diabetes mellitus. Chest. 2000;117(6):1685-1689.

32. Lin $\mathrm{Y}-\mathrm{C}, \mathrm{Tu} \mathrm{C}-\mathrm{Y}$, Chen $\mathrm{W}$, et al. An urgent problem of aerobic gram-negative pathogen infection in complicated parapneumonic effusions or empyemas. Internal Med. 2007;46(15):1173-1178. doi:10.2169/internalmedicine.46.6451

33. Tu C-Y, Hsu W-H, Hsia T-C, et al. The changing pathogens of complicated parapneumonic effusions or empyemas in a medical intensive care unit. Intensive Care Med. 2006;32(4):570-576. doi:10.1007/s00134-005-0064-7

34. Richet H. Seasonality in Gram-negative and healthcare-associated infections. Clin Microbiol Infect. 2012;18(10):934-940. doi:10.1111/j.1469-0691.2012.03954.x

35. Hassan M, Corcoran JP, Daneshvar C. Factors associated with variations in the rate of referrals and microbiology of pleural infection. Expert Rev Respir Med. 2020;14(11):1165-1171. doi:10.1080/17476348.2020.1804874

36. Corcoran JP, Wrightson JM, Belcher E, DeCamp MM, FellerKopman D, Rahman NM. Pleural infection: past, present, and future directions. Lancet Respir Med. 2015;3(7):563-577. doi:10.1016/S2213-2600(15)00185-X

37. Boyanova L, Djambazov V, Gergova G, et al. Anaerobic microbiology in 198 cases of pleural empyema: a Bulgarian study. Anaerobe. 2004;10(5):261-267. doi:10.1016/j. anaerobe.2004.06.001

38. Dyrhovden R, Nygaard RM, Patel R, Ulvestad E, Kommedal Ø. The bacterial aetiology of pleural empyema. A descriptive and comparative metagenomic study. Clin Microbiol Infect. 2019;25 (8):981-986. doi:10.1016/j.cmi.2018.11.030

39. Ko SC, Chen KY, Hsueh PR, Luh KT, Yang PC. Fungal empyema thoracis: an emerging clinical entity. Chest. 2000;117 (6):1672-1678.

40. Bedawi EO, Hassan M, Rahman NM. Recent developments in the management of pleural infection: a comprehensive review. Clin Respir J. 2018;12(8):2309-2320. doi:10.1111/crj.12941

41. Brixey AG, Luo Y, Skouras V, Awdankiewicz A, Light RW. The efficacy of chest radiographs in detecting parapneumonic effusions: the efficacy of chest radiographs. Respirology. 2011;16 (6):1000-1004. doi:10.1111/j.1440-1843.2011.02006.x

42. Tsujimoto N, Saraya T, Light RW, et al. A simple method for differentiating complicated parapneumonic effusion/empyema from parapneumonic effusion using the split pleura sign and the amount of pleural effusion on thoracic CT. PLoS One. 2015;10 (6):e0130141. doi:10.1371/journal.pone.0130141

43. Porcel JM, Pardina M, Alemán C, Pallisa E, Light RW, Bielsa S. Computed tomography scoring system for discriminating between parapneumonic effusions eventually drained and those cured only with antibiotics: CT for parapneumonic effusions. Respirology. 2017;22(6):1199-1204. doi:10.1111/resp.13040
44. Kearney SE, Davies CW, Davies RJ, Gleeson FV. Computed tomography and ultrasound in parapneumonic effusions and empyema. Clin Radiol. 2000;55(7):542-547. doi:10.1053/ crad.1999.0480

45. Reissig A, Copetti R, Mathis G, et al. Lung ultrasound in the diagnosis and follow-up of community-acquired pneumonia: a prospective, multicenter, diagnostic accuracy study. Chest. 2012;142(4):965-972. doi:10.1378/chest.12-0364

46. Hassan M, Mercer RM, Rahman NM. Thoracic ultrasound in the modern management of pleural disease. Eur Respir Rev. 2020;29 (156):190136. doi:10.1183/16000617.0136-2019

47. Colice GL, Curtis A, Deslauriers J, et al. Medical and surgical treatment of parapneumonic effusions: an evidence-based guideline. Chest. 2000;118(4):1158-1171. doi:10.1378/chest.118.4.1158

48. Varsamas C, Kalkanis A, Gourgoulianis KI, Malli F. The use of a novel quantitative marker of echogenicity of pleural fluid in parapneumonic pleural effusions. Can Respir J. 2020;2020:1283590. doi:10.1155/2020/1283590

49. Heffner JE, Brown LK, Barbieri C, DeLeo JM. Pleural fluid chemical analysis in parapneumonic effusions. A meta-analysis. Am J Respir Crit Care Med. 1995;151(6):1700-1708. doi:10.1164/ajrccm.151.6.7767510

50. Maskell NA, Gleeson FV, Darby M, Davies RJO. Diagnostically significant variations in pleural fluid $\mathrm{pH}$ in loculated parapneumonic effusions. CHEST. 2004;126(6):2022-2024. doi:10.1378/ chest.126.6.2022

51. Isenstein D, Honig E. Proteus vulgaris empyema and increased pleural fluid pH. CHEST. 1990;97(2):511. doi:10.1378/ chest.97.2.511b

52. Fitzgerald DB, Leong SL, Budgeon CA, et al. Relationship of pleural fluid $\mathrm{pH}$ and glucose: a multi-centre study of 2,971 cases. J Thorac Dis. 2019;11(1):123-130. doi:10.21037/jtd.2018.12.101

53. Falguera M, Carratalà J, Bielsa S, et al. Predictive factors, microbiology and outcome of patients with parapneumonic effusion. Eur Respir J. 2011;38(5):1173. doi:10.1183/09031936.00000211

54. Porcel JM, Bielsa S, Esquerda A, Ruiz-González A, Falguera M. Pleural fluid C-reactive protein contributes to the diagnosis and assessment of severity of parapneumonic effusions. Eur J Intern Med. 2012;23(5):447-450. doi:10.1016/j.ejim.2012.03.002

55. Porcel JM, Valencia H, Bielsa S. Factors influencing pleural drainage in parapneumonic effusions. Revista Clínica Española. 2016;216(7):361-366. doi:10.1016/j.rce.2016.04.004

56. Menzies SM, Rahman NM, Wrightson JM, et al. Blood culture bottle culture of pleural fluid in pleural infection. Thorax. 2011;66 (8):658. doi:10.1136/thx.2010.157842

57. Dixon G, Lama-Lopez A, Bintcliffe OJ, Morley AJ, Hooper CE, Maskell NA. The role of serum procalcitonin in establishing the diagnosis and prognosis of pleural infection. Respir Res. 2017;18 (1):30. doi:10.1186/s12931-017-0501-5

58. McCann FJ, Chapman SJ, Yu WC, Maskell NA, Davies RJO, Lee YCG. Ability of procalcitonin to discriminate infection from non-infective inflammation using two pleural disease settings. PLoS One. 2012;7(12):e49894. doi:10.1371/journal.pone.0049894

59. Insa R, Marín M, Martín A, et al. Systematic use of universal 16S rRNA Gene Polymerase Chain Reaction (PCR) and sequencing for processing pleural effusions improves conventional culture techniques. Medicine. 2012;91(2):103-110. doi:10.1097/ MD.0b013e31824dfdb0

60. Gadsby NJ, Russell CD, McHugh MP, et al. Comprehensive molecular testing for respiratory pathogens in community-acquired pneumonia. Clin Infect Dis. 2016;62 (7):817-823. doi:10.1093/cid/civ1214

61. Zhou F, Sun S, Sun X, Chen Y, Yang X. Rapid and sensitive identification of pleural and peritoneal infections by droplet digital PCR. Folia Microbiol. 2021;66(2):213-219. doi:10.1007/ s12223-020-00834-0 
62. Franchetti L, Schumann DM, Tamm M, Jahn K, Stolz D. Multiplex bacterial polymerase chain reaction in a cohort of patients with pleural effusion. BMC Infect Dis. 2020;20(1):99. doi:10.1186/s12879-020-4793-6

63. Teixeira LR, Sasse SA, Villarino MA, Nguyen T, Mulligan ME, Light RW. Antibiotic levels in empyemic pleural fluid. Chest. 2000;117(6):1734-1739. doi:10.1378/chest.117.6.1734

64. Bhatnagar R, Skouras VS, Rahman NM, Psallidas I. Antibiotics for pleural infections. In: Aliberti S, Chalmers JD, Pletz MW editors. Anti-Infectives and the Lung. European Respiratory Society; 2017:253-263. doi:10.1183/2312508X.10005816.

65. Shen KR, Bribriesco A, Crabtree T, et al. The American Association for Thoracic Surgery consensus guidelines for the management of empyema. J Thorac Cardiovasc Surg. 2017;153 (6):e129-e146. doi:10.1016/j.jtcvs.2017.01.030

66. Porcel JM, Ferreiro L, Rumi L, et al. Two vs. three weeks of treatment with amoxicillin-clavulanate for stabilized community-acquired complicated parapneumonic effusions. A preliminary non-inferiority, double-blind, randomized, controlled trial. Pleura Peritoneum. 2020;5(1). doi:10.1515/pp2019-0027

67. Ng T, Ryder BA, Maziak DE, Shamji FM. Treatment of postpneumonectomy empyema with debridement followed by continuous antibiotic irrigation. $J$ Am Coll Surg. 2008;206 (6):1178-1183. doi:10.1016/j.jamcollsurg.2008.01.005

68. Rana MA, Rahman BAE, Mady AF, et al. Intra-pleural colistin methanesulfonate therapy for pleural infection caused by carbapenem-resistant acinetobacter baumannii: a successful case report. Infect Dis Rep. 2014;6:3. doi:10.4081/idr.2014.5413

69. Chao Y-K, Lee C-H, Liu K-S, Wang Y-C, Wang C-W, Liu S-J. Sustained release of bactericidal concentrations of penicillin in the pleural space via an antibiotic-eluting pigtail catheter coated with electrospun nanofibers: results from in vivo and in vitro studies. Int J Nanomedicine. 2015;10:3329-3336. doi:10.2147/ IJN.S82228

70. Rahman NM, Maskell NA, Davies CWH, et al. The relationship between chest tube size and clinical outcome in pleural infection. CHEST. 2010;137(3):536-543. doi:10.1378/chest.09-1044

71. Rahman NM, Maskell NA, West A, et al. Intrapleural use of tissue plasminogen activator and DNase in pleural infection. $N$ Engl J Med. 2011;365(6):518-526. doi:10.1056/NEJMoa1012740

72. Karandashova S, Florova G, Azghani AO, et al. Intrapleural adenoviral delivery of human plasminogen activator inhibitor-1 exacerbates tetracycline-induced pleural injury in rabbits. $\mathrm{Am}$ $J$ Respir Cell Mol Biol. 2013;48(1):44-52. doi:10.1165/ rcmb.2012-0183OC

73. Idell S, Florova G, Shetty S, et al. Precision-guided, personalized intrapleural fibrinolytic therapy for empyema and complicated parapneumonic pleural effusions: the case for the fibrinolytic potential. Clin Pulm Med. 2017;24(4):163-169. doi:10.1097/ CPM.0000000000000216

74. Zhu Z, Hawthorne ML, Guo Y, et al. Tissue plasminogen activator combined with human recombinant deoxyribonuclease is effective therapy for empyema in a rabbit model. CHEST. 2006;129(6):1577-1583. doi:10.1378/chest.129.6.1577

75. Piccolo F, Pitman N, Bhatnagar R, et al. Intrapleural tissue plasminogen activator and deoxyribonuclease for pleural infection. an effective and safe alternative to surgery. Annals ATS. 2014;11 (9):1419-1425. doi:10.1513/AnnalsATS.201407-329OC

76. Porcel JM. Dual intracavitary therapy for pleural infections: leaving reluctance behind. Eur Respir J. 2019;54(2):1901001. doi:10.1183/13993003.01001-2019

77. Diacon AH, Theron J, Schuurmans MM, Van de Wal BW, Bolliger CT. Intrapleural streptokinase for empyema and complicated parapneumonic effusions. Am J Respir Crit Care Med. 2004;170(1):49-53. doi:10.1164/rccm.200312-1740OC
78. Davies RJ, Traill ZC, Gleeson FV. Randomised controlled trial of intrapleural streptokinase in community acquired pleural infection. Thorax. 1997;52(5):416-421. doi:10.1136/thx.52.5.416

79. Maskell NA, Davies CWH, Nunn AJ, et al. U.K. controlled trial of intrapleural streptokinase for pleural infection. $N$ Engl J Med. 2005;352(9):865-874. doi:10.1056/NEJMoa042473

80. Gervais DA, Levis DA, Hahn PF, Uppot RN, Arellano RS, Mueller PR. Adjunctive intrapleural tissue plasminogen activator administered via chest tubes placed with imaging guidance: effectiveness and risk for hemorrhage. Radiology. 2008;246 (3):956-963. doi:10.1148/radiol.2463070235

81. Kheir F, Cheng G, Rivera E, et al. Concurrent versus sequential intrapleural instillation of tissue plasminogen activator and deoxyribonuclease for pleural infection. $J$ Bronchology Interv Pulmonol. 2018;25(2):125-131. doi:10.1097/LBR.00000000 00000461

82. Majid A, Kheir F, Folch A, et al. Concurrent intrapleural instillation of tissue plasminogen activator and dnase for pleural infection. A Single-center experience. Ann Am Thorac Soc. 2016;13 (9):1512-1518. doi:10.1513/AnnalsATS.201602-1270C

83. Popowicz N, Bintcliffe O, De Fonseka D, et al. Dose de-escalation of intrapleural tissue plasminogen activator therapy for pleural infection. The Alteplase dose assessment for pleural infection therapy project. Ann Am Thorac Soc. 2017;14 (6):929-936. doi:10.1513/AnnalsATS.201609-673OC

84. Chambers A, Routledge T, Dunning J, Scarci M. Is video-assisted thoracoscopic surgical decortication superior to open surgery in the management of adults with primary empyema? Interact Cardiovasc Thorac Surg. 2010;11:171-177. doi:10.1510/ icvts.2010.240408

85. Yeung C, Dawson J, Gilbert S. Uniportal video-assisted thoracoscopy approach to the management of non-pulmonary diseases of the chest. J Thorac Dis. 2019;11(S16):S2062-S2068. doi:10.210 37/jtd.2019.03.21

86. Migliore M. Nonintubated uniportal video-assisted thoracic surgery for chest infections. Thorac Surg Clin. 2020;30(1):33-39. doi:10.1016/j.thorsurg.2019.08.004

87. Suchar AM, Zureikat AH, Glynn L, Statter MB, Lee J, Liu DC. Ready for the frontline: is early thoracoscopic decortication the new standard of care for advanced pneumonia with empyema? Am Surg. 2006;72(8):688-693. doi:10.1177/00031348060 7200806

88. Marks DJB, Fisk MD, Koo CY, et al. Thoracic empyema: a 12-year study from a UK tertiary cardiothoracic referral centre. PLoS One. 2012;7(1):e30074-e30074. doi:10.1371/journal. pone. 0030074

89. Bilgin M, Akcali Y, Oguzkaya F. Benefits of early aggressive management of empyema thoracis. ANZ J Surg. 2006;76 (3):120-122. doi:10.1111/j.1445-2197.2006.03666.x

90. Mondoni M, Saderi L, Trogu F, et al. Medical thoracoscopy treatment for pleural infections: a systematic review and meta-analysis. BMC Pulm Med. 2021;21(1):127. doi:10.1186/ s12890-021-01492-9

91. Kheir F, Thakore S, Mehta $\mathrm{H}$, et al. Intrapleural fibrinolytic therapy versus early medical thoracoscopy for treatment of pleural infection. randomized controlled clinical trial. Ann Am Thorac Soc. 2020;17(8):958-964. doi:10.1513/AnnalsATS.2 02001-0760C

92. Brutsche MH, Tassi G-F, Györik S, et al. Treatment of sonographically stratified multiloculated thoracic empyema by medical thoracoscopy. Chest. 2005;128(5):3303-3309. doi:10.1378/ chest.128.5.3303

93. Tassi GF, Marchetti GP, Pinelli V, Chiari S. Practical management of pleural empyema. Monaldi Arch Chest Dis. 2010;73 (3):124-129. doi:10.4081/monaldi.2010.296 
94. Sumalani KK, Rizvi NA, Asghar A. Role of medical thoracoscopy in the management of multiloculated empyema. BMC Pulm Med. 2018;18(1):179. doi:10.1186/s12890-018-0745-y

95. Hooper CE, Edey AJ, Wallis A, et al. Pleural irrigation trial (PIT): a randomised controlled trial of pleural irrigation with normal saline versus standard care in patients with pleural infection. Eur Respir J. 2015;46(2):456. doi:10.1183/09031936.00147214

96. Porcel JM, Valencia H, Bielsa S. Manual intrapleural saline flushing plus urokinase: a potentially useful therapy for complicated parapneumonic effusions and empyemas. Lung. 2017;195 (1):135-138. doi:10.1007/s00408-016-9964-2

97. Light RW. Parapneumonic effusions and empyema. Proc Am Thorac Soc. 2006;3(1):75-80. doi:10.1513/pats.200510-113JH

98. Togo S, Ouattara MA, Sangaré I, et al. Management for pediatric pleural empyema in resource-poor country: is chest tube drainage with antiseptic lavage-irrigation better than tube thoracostomy alone? SS. 2015;06(12):541-548. doi:10.4236/ss.2015.612077

99. Jouneau S, Letheulle J, Desrues B. Repeated therapeutic thoracentesis to manage complicated parapneumonic effusions. Curr Opin Pulm Med. 2015;21(4):387-392. doi:10.1097/MCP.0000000000000171

100. Letheulle J, Tattevin P, Saunders L, et al. Iterative thoracentesis as first-line treatment of complicated parapneumonic effusion. PLoS One. 2014;9(1):e84788. doi:10.1371/journal.pone.0084788

101. Nielsen J, Meyer CN, Rosenlund S. Outcome and clinical characteristics in pleural empyema: a retrospective study. Scand J Infect Dis. 2011;43(6-7):430-435. doi:10.3109/00365548.2011.562527

102. Marks DJB, Fisk MD, Koo CY, et al. Thoracic Empyema: a 12-year study from a uk tertiary cardiothoracic referral centre. Wilkinson RJ, ed. PLoS One. 2012;7(1):e30074. doi:10.1371/ journal.pone.0030074

103. Heffner JE, McDonald J, Barbieri C, Klein J. Management of parapneumonic effusions. An analysis of physician practice patterns. Arch Surg. 1995;130(4):433-438. doi:10.1001/ archsurg.1995.01430040095021

104. Lindstrom ST, Kolbe J. Community acquired parapneumonic thoracic empyema: predictors of outcome. Respirology. 1999;4(2):173-179.
105. Park C-K, Oh H-J, Choi H-Y, et al. Microbiological characteristics and predictive factors for mortality in pleural infection: a single-center cohort study in Korea. Trottein F, ed. PLoS One. 2016;11(8):e0161280. doi:10.1371/journal. pone. 0161280

106. Søgaard M, Nielsen RB, Nørgaard M, Kornum JB, Schønheyder HC, Thomsen RW. Incidence, length of stay, and prognosis of hospitalized patients with pleural empyema. Chest. 2014;145(1):189-192. doi:10.1378/chest.13-1912

107. Ferguson AD, Prescott RJ, Selkon JB, Watson D, Swinburn CR. The clinical course and management of thoracic empyema. QJM. 1996;89(4):285-289. doi:10.1093/qjmed/89.4.285

108. Davies CW, Kearney SE, Gleeson FV, Davies RJ. Predictors of outcome and long-term survival in patients with pleural infection. Am J Respir Crit Care Med. 1999;160(5 Pt 1):1682-1687. doi:10.1164/ajrccm.160.5.9903002

109. White HD, White BAA, Song J, Fader R, Quiroga P, Arroliga AC. Pleural infections: a 9-year review of bacteriology, case characteristics and mortality. Am J Med Sci. 2013;345 (5):349-354. doi:10.1097/MAJ.0b013e318259bd24

110. Chen C-H, Chen W, Chen H-J, et al. Transthoracic ultrasonography in predicting the outcome of small-bore catheter drainage in empyemas or complicated parapneumonic effusions. Ultrasound Med Biol. 2009;35(9):1468-1474. doi:10.1016/j.ultrasme dbio.2009.04.021

111. Wu J, Liu C, Lee S, Kuo Y, Hsieh T. Assessment of the charlson comorbidity index score, CHADS2 and CHA2DS2-VASc scores in predicting death in patients with thoracic empyema. Heart Lung. 2018;47(2):157-161. doi:10.1016/j.hrtlng.2017.12.003

112. Porcel JM. PILOTing towards a RAPID predictor of mortality for infectious pleural effusions. Eur Respir J. 2020;56(5):2002425. doi:10.1183/13993003.02425-2020
International Journal of General Medicine

\section{Publish your work in this journal}

The International Journal of General Medicine is an international, peer-reviewed open-access journal that focuses on general and internal medicine, pathogenesis, epidemiology, diagnosis, monitoring and treatment protocols. The journal is characterized by the rapid reporting of reviews, original research and clinical studies

\section{Dovepress}

across all disease areas. The manuscript management system is completely online and includes a very quick and fair peer-review system, which is all easy to use. Visit http://www.dovepress.com/ testimonials.php to read real quotes from published authors. 